\title{
Mega-Regionalism in Southeast Asia: Single- and Dual-Track Options for ASEAN Member States
}

\author{
Kiki Verico ${ }^{1}\left(\mathbb{D} \theta^{\mathrm{a}}\right.$ \\ 1 The LPEM, Department of Economics, Faculty of Economics and Business, University of Indonesia, Indonesia \\ Keywords: economic integration, neoclassical models of trade, cross-country convergence \\ https://doi.org/10.46557/001c.27139
}

Asian Economics Letters

Vol. 3, Issue 1, 2022

This paper compares the effects of the economic convergence levels of the two mega-regional cooperative efforts of the Comprehensive and Progressive Agreement for Trans-Pacific Partnership (CPTPP) and the Regional Comprehensive Economic Partnership (RCEP) on the Association of Southeast Asian Nations (ASEAN). It finds that the single track of the RCEP has preserved a balance between open regionalism and economic convergence that better fits ASEAN economic features compared to the dual track of both the RCEP and CPTPP.

\section{Introduction}

Mega-regional cooperation involving the Association of Southeast Asian Nations (ASEAN) members is essential for its open regionalism strategy known as the ASEAN Plus Frameworks (e.g., ASEAN+1, Free Trade Agreement (FTA), ASEAN+3, and ASEAN+6) to increase non-member investment (Verico, 2017). Open regionalism is necessary in any mega-regional cooperation, but it is incomplete without sufficient economic convergence.

This paper hypothesizes that the Regional Comprehensive Economic Partnership (RCEP) produces greater convergence for ASEAN in terms of economic integration than the Comprehensive and Progressive Agreement for TransPacific Partnership (CPTPP). The difference between the CPTPP and the RCEP is that the RCEP consists of all 10 ASEAN member states, whereas the CPTPP includes only four ASEAN members. The RCEP upholds the centrality of ASEAN, whereas the CPTPP does not. Therefore, it is essential to compare the effects of the economic convergence of both mega-regional types of cooperation on the ASEAN economy.

Previous studies using the Global Trade Analysis Project (GTAP) model find that, at the regional level, the open regionalism of the RCEP generates higher economic impact than the closed regionalism of the CPTPP (Ji et al., 2018). The RCEP decreases tariff rates, simplifies intra-trade paperwork, supports the supply chain through increasing intra-investment, and is in line with expanding intra-industry trade in Southeast Asia (Bhaskaran, 2020). The RCEP upholds the centrality of ASEAN and can balance between the soft open regionality and convergence centrality of ASEAN members (Kliem, 2019).

The CPTPP was previously known as the Trans-Pacific Partnership (TPP), but it changed its name in March 2018, after the withdrawal of the United States. Today, the CPTPP is still the most comprehensive mega-regional economic cooperative effort with the highest-quality regional trade agreement. However, because not all ASEAN members have become CPTPP members, they have the potential for an increase in economic divergence.

The novelty of this study is that it has found the RCEP to preserve ASEAN economic convergence and fulfill the needs of ASEAN in terms of investment. Therefore, this paper argues that the single track of the RCEP would better fit ASEAN's character than the dual track of both the RCEP and the CPTPP.

\section{Data and Methodology}

This paper has adopted the methods of revealed comparative advantage (RCA) and constant market share analysis (CMSA). The combination of RCA and CMSA is used to reveal the CPTPP's and the RCEP's trade and long-run investment relations. The paper analyzes both indicators using the Harmonized System 2 (HS2) dataset. The analysis period for all indicators covers the last five years, including the period before the global COVID-19 pandemic, to obtain a typical picture, without the impact of the pandemic. This paper uses the year 2019 as a static indicator for RCA, and 2015 and 2019 for dynamic indicators of CMSA3. Our data is sourced from TradeMap database. ${ }^{1}$

The equations used are

\footnotetext{
a Corresponding author email: kiki.verico@ui.ac.id
}

1 See https://www.trademap.org/Index.aspx. 


$$
R C A_{i j t}=\frac{X_{i j t} / \sum_{i=1}^{i=n} X_{j t}}{X_{i w t} / \sum_{i=1}^{i=n} X_{j t}}
$$

where $i$ indicates a tradable export $(X)$ good from country $j$ at time $t, w$ denotes the world, and $n$ denotes the latest HS4 tradable goods, and

$$
\begin{aligned}
C M S A_{i j t}= & X_{i j t 1}-X_{i j t 0} \\
= & \sum\left(X_{i w \Delta t}\right) \cdot X_{i j t 0}-X_{i j t 0} \\
& +\left(X_{i w \Delta t}-\sum X_{i w \Delta t}\right) \cdot X_{i j t 0} \\
& +\left(X_{i j t 1}-X_{i w \Delta t} \cdot X_{i j t 0}\right)
\end{aligned}
$$

Where $\sum\left(X_{i w \Delta t}\right) \cdot X_{i j t 0}-X_{i j t 0}$ is the general factor (CMSA1); $\left(X_{i w \Delta t}-\sum X_{i w \Delta t}\right) . X_{i j t 0}$ is the composition factor (CMSA2); and $\left(X_{i j t 1}-X_{i w j \Delta t} . X_{i j t 0}\right)$ is the comparative factor (CMSA3).

This paper uses RCA and the comparative factor (CMSA3) to determine whether the product's industry is classified as a great industry (RCA $>1$, CMSA3 $>0$ ), a sunrise industry (RCA $<1$, CMSA3 $>0$ ), a sunset industry (RCA $>1$, CMSA 30$)$, or a poor industry $(\mathrm{RCA}<1$, CMSA $<0)$. This classification is essential to compare a sunrise industry's investment in one country to that of a sunset industry in another (Verico, 2020). Additionally, it describes the degree of investment and industrial integration by comparing the total numbers of great and sunrise industries and of sunset and poor industries.

The investment degree of each mega-regional organization is calculated as

$$
\lambda_{m t}=\frac{\sum \gamma_{n i t}}{\sum \vartheta_{n i t}}
$$

where, at time $t, \vartheta_{\text {int }}$ is the investment degree of mega-region $m, \gamma_{i n t}$ is the number of sunrise industries in a country of $n$ products of good $i$, and $\vartheta_{\text {int }}$ is number of sunset industries in a country of $n$ products of good $i$. If the investment degree is greater than one, then mega-regional cooperation can extend its economic cooperation from trade to investment.

The industrial integration of each mega-regional organization is calculated as

$$
\tau_{m t}=1-\sum_{n=1}^{z}\left(\frac{\delta_{n i t}+\gamma_{n i t}-\vartheta_{n i t}+\theta_{n i t}}{\delta_{n i t}+\gamma_{n i t}}\right)
$$

where, at time $t, \tau_{m t}$ is the industrial integration of megaregion $m, \delta_{n i t}$ is the number of great industries in a country of $n$ products of good $i, \gamma_{n i t}$ is the number of sunrise industries in a country of $n$ products of good $i, \vartheta_{n i t}$ is the number of sunset industries in a country of $n$ products of good $i$, and $\theta_{\text {nit }}$ is the number of poor industries in a country of $n$ products of good $i$. The closer industrial integration is to unity, the greater the convergence of mega-regional cooperation.

This paper applies the GTAP10A model to verify the level of economic convergence, using trade balance as a short- run indicator of trade relations and the price of supply as a long-run indicator of productivity. ${ }^{2}$ It denotes the member states of the CPTPP and the RCEP as new regions, and the remainder of the world as old regions. This paper also adopts 65 old sectors mapped into 10 sectors, and eight old factors mapped into five new ones. The simulations use the shock of most favored nation and solve it with Euler's three-solution method.

The GTAP model is essential to assess the impacts of economic cooperation on both tradable and non-tradable goods. Moreover, the GTAP model is necessary to complete the RCA and CMSA3 analyses, which covers only tradable goods. This paper estimates the short-run effect with the trade balance as a proxy for trade creation, and the longrun effect with the supply price as a proxy for productivity. These measurements are novel to the literature, and they are advantageous to assess whether the RCEP's strategy fits ASEAN. Moreover, this assessment fills a gap in the literature, since it compares the CPTPP and the RCEP simultaneously with RCA, CMSA, and degrees of investment and industrial integration and confirms the results with the computable general equilibrium of GTAP analysis.

\section{Empirical Results \\ A. Qualitative Descriptive Results}

The RCEP has 10 ASEAN member states, including five new members in the ASEAN Plus Framework, which are China, Japan, South Korea, Australia, and New Zealand. On the other hand, the СРTPP has 11 member states.

The macroeconomic variable denoting the gross domestic product (GDP) per capita is valuable for analyzing potential economic relationships between countries (Verico, 2018). Therefore, this paper adopts the GDP per capita of all 19 countries to determine their relationships and uses it as an initial measure of comparative economic convergence.

Table 1 shows that South Korea is the only high-income country (HIC) that is not a member of the CPTPP, and Vietnam is the only lower middle-income country (LMIC) that is a member of both the RCEP and the CPTPP. As for upper middle-income countries (UMICs), China, Thailand, and Indonesia are members of the RCEP only, while Malaysia, Mexico, and Peru are members of both the RCEP and the CPTPP.

This composition shows that the CPTPP is biased toward HICs, while the RCEP is biased toward LMICs. This explains why the RCEP is more compatible with ASEAN's GDP per capita architecture and is thus more convergent with the ASEAN economy. The CPTPP favors HICs, while the RCEP favors LMICs. This divergence indicates that the RCEP's economic integration process is slower than that of the СРТPP. 
Table 1. Member States of RCEP, CPTPP, RCEP \& CPTPP and RCEP Only

\begin{tabular}{lllll}
\hline Number & RCEP & CPTPP & RCEP CPTPP (Dual Track) & $\begin{array}{l}\text { RCEP Only (Single Track) } \\
\text { Selected ASEAN Members }\end{array}$ \\
\hline 1 & Australia & Australia & Australia & China \\
2 & Brunei & Brunei & Japan & Indonesia \\
3 & Cambodia & Canada & Malaysia & Philippines \\
4 & China & Chile & Singapore & Thailand \\
5 & Indonesia & Japan & Vietnam & South Korea \\
6 & Japan & Malaysia & & \\
7 & Laos & Mexico & & \\
8 & Malaysia & New Zealand & & \\
9 & Myanmar & Peru & & \\
10 & New Zealand & Singapore & & \\
11 & Philippines & Vietnam & & \\
12 & Singapore & & & \\
13 & South Korea & & & \\
14 & Thailand & & & \\
15 & Vietnam & & & \\
\hline
\end{tabular}

This table shows five countries that simultaneously became member states of the CPTPP and RCEP and five countries that only registered as member states of RCEP Only. List of countries in both strategies-the dual-track strategy of the member states of CPTPP \& RCEP and the single-track strategy of selected ASEAN member states of RCEP only, are shown.

\section{B. Quantitative Simulation Results}

The combination of RCA and CMSA3 defines each of the member states' tradable products. This paper finds that the member states of both the CPTPP and RCEP have 131 products in industries classified as great, 131 in sunrise industries, 97 in sunset industries, and 126 in poor industries. However, for the member states of the RCEP only, this paper finds 278 products in industries classified as great, 226 in sunrise industries, 218 in sunset industries, and 248 in poor industries. These classifications are used to calculate two indicators: first, the degree of investment from sunrise and sunset industries within member states and, second, the level of industrial integration, a proxy of relative convergency.

Table 2 shows that mega-regional organizations have a similar capacity to transform their economic integration from trade to investment. This finding indicates that the CPTPP and RCEP are identical, since both can be independent areas with a degree of investment greater than one and both can increase intra-trade investments. This paper confirms that the member states of the RCEP only have greater convergence at the industrial integration level than the dual track of the members of both the CPTPP and RCEP (see Figure 1).

The GTAP model confirms the short- and long-run impacts on trade balance. The paper uses trade balance for the short run and the price of supply for the long run. It finds that both the CPTPP and the RCEP have a mostly negative effect on trade balance in the short run, but generate benefits in the long run from a decrease in supply prices, increasing the marginal productivity of labor. These simulation results show that the cost of trade creation is temporary in mega-regional economic cooperation, since it relates to trade, but the benefit (i.e., increased productivity) is permanent, since it relates to the supply side. The GTAP model in this paper is limited, because it assumes a constant return to scale, is static compared to time series, and the sectors are limited due to data unavailability.

\section{Conclusion}

This paper asks major questions about the economic convergence of the CPTPP and the RCEP in terms of the economy of ASEAN countries and the RCEP's ability to generate regional investment. First, this paper finds that the industrial integration level of single-track member states converges more than that of the dual track. It confirms that the RCEP fits well with the soft, open regionalism of the ASEAN strategy. Second, this paper finds that the RCEP's degree of investment is greater than unity. This result demonstrates that the RCEP could generate investment in its region. From the ASEAN perspective, open regionalism is necessary and economic convergence is sufficient. This paper thus contributes to demonstrating that the RCEP's single track fulfills ASEAN's sufficient conditions. Further research is needed to confirm how stable the RCEP is for this purpose.

\section{Acknowledgment}

I would like to thank the Editor and the anonymous reviewers for their priceless reviews and advice. The usual disclaimer applies.

Submitted: March 29, 2021 AEST, Accepted: July 02, 2021 AEST 
Table 2. Investment degree and industrial integration level of CPTPP \& RCEP and RCEP only

\begin{tabular}{lllll}
\hline & CPTPP \& RCEP & \multicolumn{2}{l}{ RCEP Only } \\
\hline Great & 131 & Investment Degree & 278 & Investment Degree \\
Sunrise & 131 & 1.4 & 226 & 1.04 \\
Sunset & 97 & Industrial Integration Level & 218 & Industrial Integration Level \\
Poor & 126 & 0.85 & 248 & 0.92 \\
\hline Total & 485 & & 970 & \\
\hline
\end{tabular}

Notes: Author's own calculation based on the Trade Map - Data Availability, 2021.

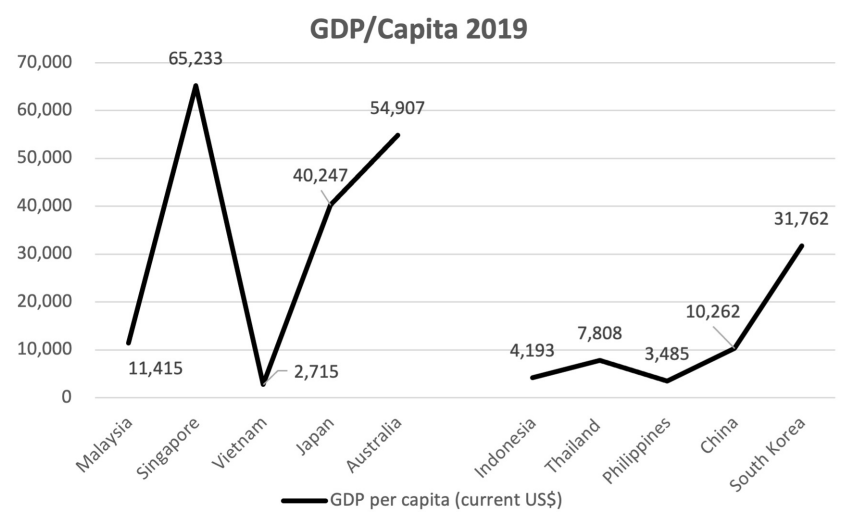

Figure 1. GDP per capita for members of the CPTPP and the RCEP and of the RCEP only

Notes: This figure demonstrates that the dual track diverges more than the single track based on the World Bank's World Development Indicator data from 2021. 


\section{References}

Bhaskaran, M. (2020). Economic Overview of Southeast Asia. Southeast Asian Affairs, 19-42. Project MUSE Economic Overview of Southeast Asia (jhu.edu).

Ji, X., Rana, P. B., Chia, W. M., \& Li, C. T. (2018). Trade Policy Options for ASEAN Countries and Their Regional Dialogue Partners: Preference Ordering Using CGE Analysis. RSIS Working Paper, 308, 1-30 NTU. https://hdl.handle.net/10356/88330

Kliem, F. (2019). Thailand's ASEAN Chairmanship at Its Mid-Term: Three Key Issues to Watch After the 34th ASEAN Summit. Rajaratnam School of International Studies, 1-15.
Verico, K. (2017). The Future of the ASEAN Economic Integration. Palgrave Macmillan. https://doi.org/10.10 57/978-1-137-59613-0

Verico, K. (2018). Modification of Regulatory Impact Assessment (RIA) Method on Indonesia's Trade, Investment and Industrial Incentive Analysis. Economics and Finance in Indonesia, 64(1), 43-58. htt ps://doi.org/10.7454/efi.v64i1.579

Verico, K. (2020). How to Measure Bilateral Economic Relations: Case of Indonesia and Australia. LPEM FEB UI Working Paper, 56, 1-11. WP LPEM_056_Dec 2020_K Verico.cdr. 